Article

\title{
Infrastructure as a Deeply Integrated Sustainable Urban Project
}

\author{
Carmela Cucuzzella $^{\dagger, *}$, Sherif Goubran ${ }^{\dagger}$ \\ Design and Computation Arts, Concordia University, Montreal, H3G 1M8, Canada \\ $\dagger$ These authors contributed equally to this work. \\ * Correspondence: Carmela Cucuzzella, Email: carmela.cucuzzella@concordia.ca.
}

\section{ABSTRACT}

This paper explores infrastructure projects that present a conscious merging between urban transformation, community development, culture, and technology through sustainable design. When urban projects successfully and meaningfully include all these dimensions, we refer to them as "blended infrastructure" projects, since they offer much more than just infrastructure. A literature review pertaining to the rejuvenation and renewal of cities reveals that infrastructure projects have the potential to be at once, smart and ecological as well as cultural and deeply integrated urban interventions. We, therefore, propose that 'blended infrastructure' projects are those that profoundly integrate anthropological and technological dimensions. These two poles are the basis of our analysis method. Our methodology, which includes a mapping tool, is used to cartograph a series of design projects. We select two sets of projects for analysis. First, we select "light infrastructure" projects that are not yet built, still in an imaginary phase, which have a common underlying positive intention of bringing sustainability to the city. Second, we select heavier, already built, infrastructure projects, those subjected to real-world constraints, i.e., economic, political, etc. These polarities (light and imagined $v s$. heavy and realized) will help test the applicability of this mapping approach on different types of infrastructures. By studying projects on either side of a spatial design spectrum, we aim to understand which types of projects have a potential to be "blended infrastructure" projects-and therefore, deeply integrated sustainable urban

\section{G Open Access}

Received: 25 March 2019

Accepted: 16 May 2019

Published: 22 May 2019

Copyright $(92019$ by the author(s). Licensee Hapres, London, United Kingdom. This is an open access article distributed under the terms and conditions of Creative Commons Attribution 4.0 International License. interventions, as key contributions to the future of our cities.

KEYWORDS: urban sustainability; sustainable design; urban infrastructure; light infrastructure; blended infrastructure; design competitions; urban resilience; urban regeneration

\section{INTRODUCTION}

Amid the global social, environmental, and technological changes we are witnessing, urban centers have garnered increased interest from researchers, practitioners, as well as governments. Upgrading existing urban centers now presents new opportunities for re-envisioning the 
future of cities and renewing their image. Today, the renewal of cities' infrastructures that could support new technologies as well as new modes of consumption and production, is becoming an imperative element for building our cities for the future [1]. In parallel, urban infrastructure projects' capacity to generate concrete social and economic benefits are increasingly being perceived as a great untapped potential, making them an integral part of cities' cultural developments [2]. Our future and envisioned cities have gathered a variety of qualifiers to define themsuch as the green-city, eco-city, sustainable-city, smart-cities, connectedcity, the social-city or experience-city [3-5]. All these visions aim to improve the quality of life and to sustainably manage natural, economic and human resources [6]. What is important to note is that from among these visions, two key approaches to infrastructure projects are clear: (1) the technological integration (seen in visions such as that of smart-cities), and (2) the social and cultural integration (seen in visions such as that of experiential-cities).

The main goal of this research is to examine, from a sustainable design lens, the intersection of the socio-cultural and technological dimensions in infrastructure projects. Focused on the imperative need for raising climate change awareness and building social capital around the present sustainability challenges [1], the paper aims to explore the various design possibilities and forms of this new type of infrastructure project, which combines the socio-cultural and technological dimensions. The paper also aims to determine appropriate approaches for these projects in the urban context of Montreal.

The first section of the paper overviews literature pertaining to the rejuvenation and regeneration of cities and urban centers-covering both socio-cultural and technological approaches. The second portion of the paper is dedicated to clarifying the methodology of the paper and is divided into three sub-sections: the first presents the mapping approach proposed to distinguish blended infrastructure projects from other design approaches; the second deals with the sampling approach used for the paper; and the third details the process of selecting the case study and the other projects analyzed from Montreal, Canada. Section four includes the detailed presentation of the case study: an international student ideas competition entitled "More than Waiting for the Bus". The competition sought designs that can complement the transit infrastructure of the city of Montreal-fitting the light infrastructure projects proposed herein. Section four also presents the cartography of the winning and mentioned design projects from the case study, and their relation to the blended infrastructure project category proposed. Section five presents a discussion of the results and, following the sampling proposed, presents a cartography of some major infrastructure projects in Montreal. Finally, the paper concludes by highlighting the practical and research significance of recognizing the notion of blended infrastructure projects in the city and the ability of the proposed mapping tool to characterize 
these projects. The conclusion also presents some of the limitations of the tool before highlighting the direction for future improvements and research.

\section{URBAN RENEWAL-SUSTAINABILITY, TECHNOLOGY AND CULTURE}

During the last decades, cities, especially those that are part of industrialized societies have witnessed major shifts in their redevelopment strategies. This shift can be traced back to the changes and challenges that are emerging within the social, economic, environmental, and cultural dimensions. In response, the traditional urban regeneration and renewal models, which mainly focus on the physical realities of spaces, have become inadequate and would benefit from more complex and multi-layered parameters [1,4]. Hakim and Roshanali [7] propose that these non-physical and sometimes non-spatial urban development supplements are important to break the vicious urban deterioration cycle where economic, socio-cultural, structural and environmental factors are highly interlinked. Since the late 1990s, urban regeneration has moved beyond revitalization to adopt a process of strategic rethinking that places renewal and redevelopment as part of the future of cities which are intrinsically linked to their cultural, environmental social and economic profiles [1]. A variety of visions have emerged in response to this shift. Two key approaches are clear: one focusing on technology as a means while the other focusing on the cultural dimension. In the next few paragraphs, some of these will be presented and compared. Additionally, the roles proposed in the literature for the infrastructure in these visions will be made explicit.

One of the visions which received significant attention in the past few years is that of smart or intelligent cities. Angelidou [6] proposes two key forces that shape smart cities: (1) urban futures, where technology is recognized as the key driver for imagining and putting into action the future city that is modern, connected, democratic and healthy, and (2) the knowledge and innovation economy, where cities and their future can be seen as intrinsically linked to the mobilization and management of knowledge and innovation. Thus, an integrated approach to smart cities would need to focus on the human and social capitals, and where "smartness" would be focused on behavioural changes and would respond to the needs, skills and interests of users [6]. In the literature, the possibility of realizing these visions, which are data-driven, connected, and responsive-is contingent on the investment and development in "smart infrastructures" such as cyber and technology infrastructures. Bisello et al. [3] propose that the "real" vision of the smart city (as opposed to the labelled smart city) can be understood as part of the broader and more holistic vision of the sustainable city. Based on such a view, which is echoed in several publications [7-10], the deployment of technological infrastructure could constitute the "smartness" of cities-such as 
information and communication technology (ICT) among others, as well as data collection and management infrastructure-are in fact aimed at optimizing and reducing energy use, sustainably managing natural and human resources and for improving the quality of life-elements which relate to the environmental and economic dimensions of sustainability [5]. Bisello et al. [3] also propose that "smartness" becomes a cross-cutting "soft" domain that intersects the hard domains of city planning such as energy infrastructure as well as transport and mobility infrastructures. Indeed, the smartness and its technologies should be understood as tools that supplement the infrastructures that constitute the visions of the sustainable city.

Alongside the technological visions of the future, the notion of cultural development has gained significant interest in the literature and in practice. Marling et al. [4] propose that culturally focused revitalization can be understood as a future vision that they name the "experience-city". In this vision, experience-driven, cultural, playful, fun and educational experiences are fused with the transformation of urban areas [4]. Grodach \& Loukaitou-Sideris [2] distinguish three key cultural development strategies: (1) entrepreneurial, which is focused on economic growth and the creation of positive city image, (2) creative class, which aims at improving the quality of life and to attract users to the creative economy, and (3) progressive, which is focused on community development and encouraging the local production of culture through arts and education. Ferilli et al. [1] propose three levels of cultural integrations in urban regeneration projects (1) cultural-led regeneration where culture is the main catalyst for regeneration, (2) cultural regeneration where culture is fully integrated in the regeneration along other sustainability domains (namely, social, environmental and economic), and (3) culture and regeneration where the notion of culture is integrated only superficially rather than strategically. The idea of cultural-led and cultural regeneration can thus be directly linked to the creative and progressive cultural development strategies. These views can help us conclude that culture, or the experience of culture in cities, becomes another soft domain in the planning of cities' interests in the "hard" domains of infrastructures. Thus, for the effective integration of culture, renewal plans must move beyond the provision of hard infrastructures to include the activation and programming of infrastructure. By looking especially at Grodach and Loukaitou-Sideris' [2] creative class and progressive approaches of cultural development, we can recognize that they move beyond the consumeristic approach of culture (i.e., touristic development, projected images, and branding strategies) to encompass the social and economic and cultural dimensions of sustainability.

We hold that the intersection of these two approaches could result in new forms of sustainable infrastructure design project. Following a similar logic to Marling et al.'s [4] definition of hybrid cultural projects we propose to name this new form "blended infrastructure projects". These 
projects can consist of major or light projects. In this context, "light" infrastructure projects are those that aim to support and complement existing "major" infrastructures, where a conscious merging between socio-cultural and technological dimensions is utilized to attain urban transformation, community development, dynamic urban experiences, local economic development, as well efficient resource management [4]. By binding the three pillars of sustainability (i.e., social, economic, environmental) through culture and technology, blended infrastructure projects can thus be understood as deeply integrated sustainable urban interventions: relevant to their urban and economic context, appropriate to their users, and most importantly, environmentally sound. Through these intersections, we can start to concretely understand the notion of "blended infrastructure projects" as urban transformation infrastructure projects that consciously fuse community development, cultural missions, and technology. These projects are well integrated within their context, effectively manage natural and energy resources, help improve the quality of life, encourage the production of local culture, and, most importantly, are activated and programmed. Bisello et al. [3] propose that smart and intelligent cities are encapsulated within the sustainable city visionwhere the social, economic, environmental and cultural dimensions are at balance. As such, we propose that blended infrastructure projects become the means for achieving this sustainable vision, which can also generate a unified brand (i.e., the city as destination), and present a sense of place that is unique, sustainable, tangible and relevant [11]. Figure 1 illustrates the relation between smart-city and cultural development strategies within the lens of sustainability, in which their sum is the potential for blended projects.

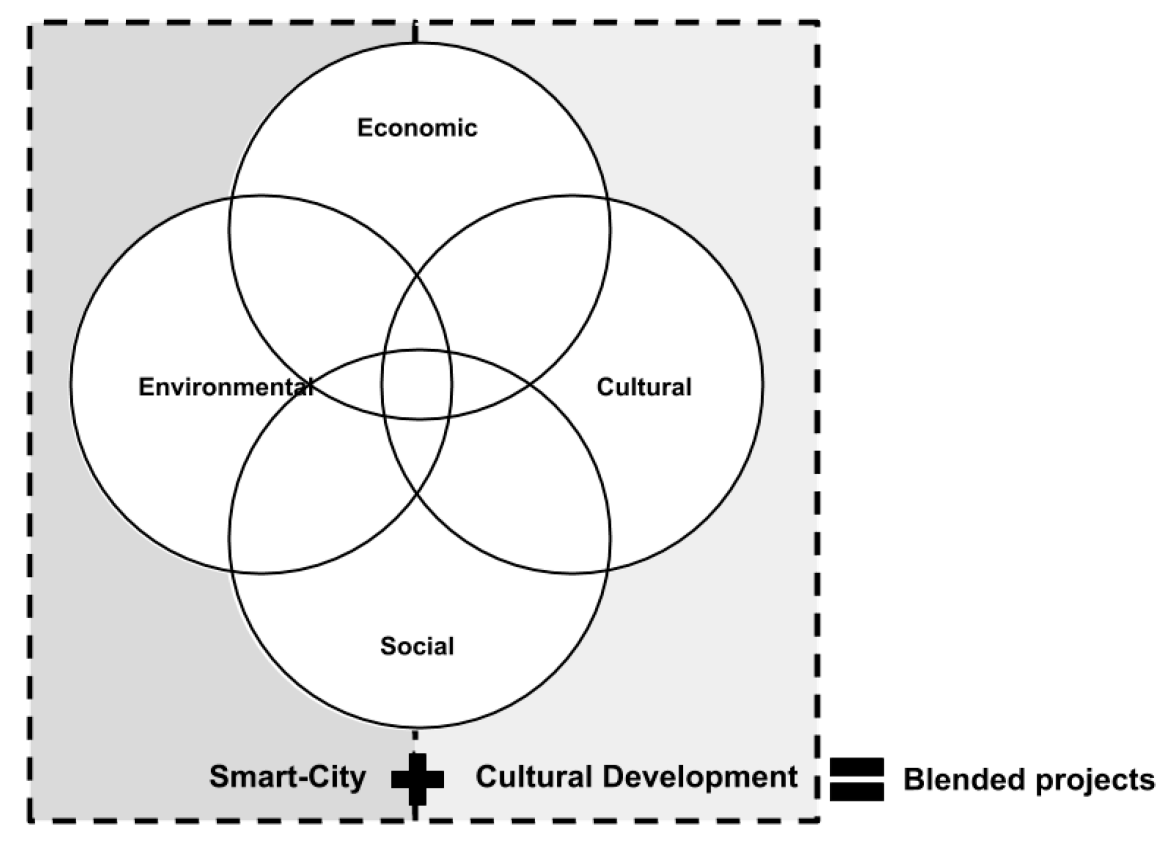

Figure 1. The relations between the pillars of sustainability, the two key approaches to urban renewal (smart city and cultural development), and the blended project. 
Based on a topological approach to urban studies, the intersecting boundaries of Figure 1 are figurative in their definition considering the complex reality of urban projects [12]. Even projects that predominantly have a smart-city approach will inevitably include some cultural development aspects. Although these complex and intertwined relations cannot be ignored or reduced to single labels, they are approached and categorized in this paper based on the implicit intention of the designers.

\section{METHODOLOGY}

\section{Mapping Urban Design Projects}

If the activity of design seeks to understand and address the "what is" of a situation, its primary goal is to conceptualize the "what can be" or the "what should be" for any given situation in order to improve it-this is the idea of projection [12-14]. Design is, therefore, a project of intentions [15] that aims to change a current situation into an improved and desired situation [14], where a conscious effort of anticipation of uncertainties is done through the process of reflection-in-action that includes, when necessary, technical rationality as defined by Schön [16]. Since projects are characterized by this ambivalent nature, then a conscious effort to anticipate the repercussions of their intentions is critical, especially when the focus is to encourage shifts in collective behaviours and on the longterm visions and their manifestations of the sustainable city [17].

According to Jean-Pierre Boutinet, anticipation or anticipative action is characterized by the fact that one must decide which course of action to take when faced with decisions or dilemmas in a situation, which include aspects of both the motivational nature and the anthropological nature of the project. The motivational nature refers to whether the underlying purpose of the project is technological innovation or is the improvement of the human condition [14,17,18]. The model by Boutinet is a good starting point and is indeed frequently adopted to analyze design and architectural projects. Specifically, Boutinet proposes to understand projects based on two main axes [14,18]: namely, the anthropological nature and the motivational nature. The anthropological nature of the project refers to the societal axis-whether the project involves collective or individual involvement [16]. In the context of urban renewal and city development, this anthropological axis can be correlated with cultural development approaches. Cucuzzella [19] also provides a mapping tool, developed in the context of sustainable architectural projects in order to better understand the emerging architectural rhetoric of environmental buildings. In her approach, projects are examined based on two main axes: (1) textually: their overall design narrative (polarity between technical vs. cultural design narrative), and (2) constructively: their visual eco-expressiveness (polarity between visible vs. non-visible eco-features). Dusch, Crilly, \& Moultrie [20] also propose a mapping tool which proposes a techno-centric axis in the design of sustainable buildings. Thus, we can propose a 
technological axis, encompassing ICT and responsive technologies, which can be considered as comprising the concerns of smart city development approaches.

By combining the approaches described by Boutinet, Cucuzzella, and Dush et al., a new analysis grid is proposed here to understand design approaches of sustainable infrastructure urban projects. Figure 2 presents this mapping tool consisting of an anthropological dimension, which encompasses the social, cultural, historic, and economic elements, and the integrated technological dimension (synergistic application of technologies, smart and inelegant features, innovations and design techniques). Within the sustainable design lens that this research adopts, the quadrants are indicative of the approaches deployed by the designers to achieve some vision of the sustainable city. Figure 2 defines the resultant four quadrants and their relation to the infrastructure projects, which can be understood as follows: (A) Non-anthropological \& Nontechnological Approach (named physical-the bottom left quadrant), where the approach can be considered or viewed as more physical and not concurrent with the new design approaches or future visions (B) Anthropologically Centered Approach (named socio-cultural-the top left quadrant) where the project lacks the deep integration of technology and rather satisfies the experience or cultural city definition described above [4], (C) Integrated Technological Approach (named smart-bottom right quadrant) where the project integrates technologies meaningfully but lacks the socio-cultural depth, and which fits the smart city vision [3], and (D) Integrated Anthropological \& Technological Approach (named blended - top right quadrant) where the design can be considered as a "blended infrastructure" project, which consciously and meaningfully fuses technological and socio-cultural elements. In these blended infrastructure projects, the design intent is founded on the 'blending' of smart and socio-cultural. To analyze infrastructure projects on the map, the architectural, spatial, and conceptual dimensions of projects must be considered. Contemporary geography, primarily adopting poststructuralist epistemologies, have demonstrated that urban realities are constituted by complex networks that combine actors, spaces and nonhuman elements [21]. This understanding, explored in the urban assemblages literature, reveals that any approach or project cannot be completely free from technological or socio-cultural characteristics: that all projects exhibit an integration of these approaches on some level [13,21,22]. The mapping approach, proposed in Figure 2, does not doubt this complexity. Instead, the mapping tool seeks to categorize projects and design approaches based on the implicit and overarching intentions of the designers-thus a blended approach is understood as a result of the conscious intent of combining smart and socio-cultural.

By utilizing the proposed map in analyzing infrastructure projects, we aim to confirm our hypothesis: "blended" projects are a new autonomous category of infrastructures, which are distinguishable and manifest 
unique urban characteristics. In order to find such projects, we adopted the following sampling methodology where such projects would most likely be present.



Figure 2. Proposed mapping tool for design approaches in infrastructure urban projects.

\section{Sampling Urban Infrastructure Projects}

Real infrastructure projects in urban centers, especially in developed countries, are complicated design endeavours and usually require the involvement of multiple stakeholders. From the initial imagined design proposal to the final realized form, many limitations emerge and changes are inevitable [23]. Thus, we can imagine a topological axis for infrastructure projects that moves from the original imagined idea to the fully realized project-in this paper, the axis is called "level of realization". If we use Boutinet's [15] concept of anticipation in projects, we can infer that the original idea includes a high degree of anticipation, which then reaches a level of zero (0) in the constructed project. Additionally, we have tried to distinguish two types of infrastructure projects that are apparent in modern cities: (1) major infrastructure projects, which are focused on augmenting the level of services and capacity of cities (including bridges, major highways, ports, etc.), and (2) light infrastructure projects, which mainly focus on improving the quality of service in existing infrastructures (including landscape improvements, quality of urban life through urban furniture, interactive media, etc.). There is no clear boundary that separates these two categories. Instead, we propose a topological axis with a continuous variation-this axis is called in this paper the "Project Nature". Figure 3 presents the two axes described.

Since this research paper constitutes a first step in the exploration of blended infrastructure projects, the proposed sample for the case study is focused on light projects that fall within the imagined design pole, of the level of realization axis. These light and imaged projects show more freedom when compared to the limitations imposed by realized projects, 
and include a small number of complex design parameters. Major infrastructure projects often undergo many political discussions and tensions that charge them with many connotations-relating to modes of production, means of economy, political aims or political power. Light and imagined infrastructure projects are not yet heavily charged connotationally-their political, environmental, social, and cultural values are still in the process of being defined. Our sampling hypothesis states that: these projects are a fertile starting point for exploring blended infrastructure projects, including their design approaches and their distinction from other smart or cultural design projects (this selection is highlighted in dark grey in Figure 3).

The framework proposed does not explicitly consider the underlying complexities that shape urban realities or the processes of urban planning. It also does not put into question the value of the project. In order to mitigate and to provide meaningful assessment, the sampling has to consider projects with shared underlying value. For this paper, the selected projects had to have an explicit focus on sustainability-in order to assume that these projects have a collective positive value of bringing sustainability in the city. Although the aim of the framework is to assess the intentions of the designs (or designers), these intentions are not always clear in large projects. The use of the framework to assess major built projects then raises many questions around urban assemblages: relating to value, power and conflicts.

However, in order to be able to test the applicability of the proposed mapping tool in the context of constructed infrastructure projects, we will also attempt in the discussion section of the paper to analyze a group of realized infrastructure projects in Montreal that vary in their naturefrom light to major (selection highlighted in light grey in Figure 3). The paper highlights how the mapping of these Montreal projects, which do not have similar values embedded within them, may be problematic since it leads to the emergence of larger value and ethical questions.

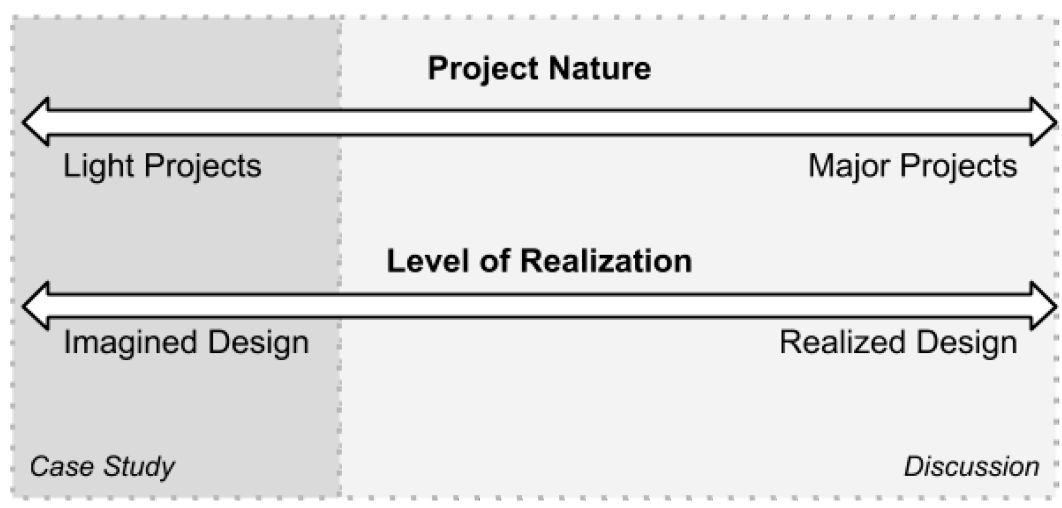

Figure 3. Polarities exhibited by infrastructure projects. 


\section{Competitions as a means for development in the city}

Why are competitions an exemplary source for studying light and imagined infrastructure projects in the city? Competitions can be viewed as epistemological devices that allow us to comparatively study interdisciplinary issues related to contemporary design projectsincluding infrastructure projects. Competitions display the best of what designers can produce, and their proposals are filtered through a comparative apparatus regulated by a collective and qualitative judgment process. This collective process provides a means for the observation and identification of design reorientations as representing the best of what architects offer. Historically, competitions have acted as both controversial and experimental events in the design disciplines [23-26]. Additionally, sustainable design interests many fields of social and cultural studies [27,28]. An understanding of how designers design for sustainability through the study of competition projects has already unveiled a series of tensions between the cultural and technical dimensions of their work [29]. This paper focuses on and analyses the winning projects of one specific case study competition, the second international design competition organized by the research initiative called CoLLaboratoire.

\section{CoLLaboratoire: An abridged theoretical background and the research initiative}

CoLLaboratoire is a research initiative launched in 2015 as part of the program of the Concordia University Research Chair Integrated Design, Ecology, and Sustainability for the Built Environment (www.ideas-be.ca), directed by Dr. Carmela Cucuzzella. This initiative, primarily a knowledge dissemination platform, focuses on understanding how design in the public realm can embody sustainable urban, professional and community practices in the long term. This initiative is motivated by the growing limitations in current practices for the sustainable built environment.

Increasingly, technical solutions to sustainability, which are based on highly structured principles that largely seek ever more eco-efficiency [28,29], have revealed several limitations due to the normative nature of their analyses tools, their fragmented project analysis processes, and their lack of awareness to the crucial social and cultural questions [29,30]. We can already identify three paradoxes resulting from these types of sustainable design practices:

- human behaviour is hardly considered in environmental evaluations, yet behaviour is at the core of environmental degradation and specifically resource consumption [23,31],

- predicted performance measurements of design projects rely on managerial and eco-deterministic approaches, yet there is a large gap between these promises based on best case scenarios and actual performance [29-32], and 
- representations of "green" design are often added to spaces or buildings to communicate the 'greenness' of these projects rather than integrating actual effective environmental processes or characteristics not necessarily visible to the general user of these spaces or buildings $[20,29,32]$.

It may be that some of the predominant international discourses and approaches have to be reconsidered in order to re-position humans at the center of climate change issues, to move away from demonstrative ecological add-ons, and rather towards critical integration [19,29,32]. CoLLaboratoire aims to address these paradoxes. The projects planned through the CoLLaboratoire platform, are designed and built with the intent of heightening climate change awareness. Through this platform, connections between academics, community members, designers, artists and different local and regional organizations are made with the aim of improving the quality of the built environment and the quality of the experience in available infrastructure. This research initiative, therefore, aims to improve the quality of life of the different involved stakeholders by helping them mobilize, collaborate and build strong networks for tackling today's sustainability challenges.

Through the design of installations in the public realm, CoLLaboratoire seeks to stimulate the collective intelligence [33] of Montreal by recovering memories of place and environment. All urban interventions are planned for Sherbrooke Street, an iconic street which continues to be a vital artery for the city, a vibrant venue for art and design initiatives and projects and that has a historic significance for artists and designers [34]. These public space installations are intended to create an urban narrative along Sherbrooke Street that will bring the conversation of these 'simple' yet complex world-wide problematics into a local context [35]. These smallscale urban interventions serve as elements of a path to a sustainable, resilient future. Resilience, as it relates to the city, does not only mean to be able to cope, survive and adapt, in extreme situations, floods, storms, attacks, fire, but it also refers to the capacity for individuals, communities, institutions, and infrastructure (in other words both soft and hard structures) within a city to prosper and to flourish in their environments. Public awareness of natural systems and resilient urban infrastructure can be fostered both during the design phase and during the use of the built public artwork. This may also have the added benefit of invigorating life in the city while addressing the pressing problems of today. The CoLLaboratoire platform is founded on these principles.

\section{Case Study: "More than Waiting for the Bus"}

"More than Waiting for the Bus" was an international student ideas competition which was concluded in April 2017. This competition was conducted in partnership with ILEAU [36] of the Conseil régional de l'environnement de Montréal (CRE-Montréal) and Chaire de recherche sur 
les concours et les pratiques contemporaines en architecture de l'Université de Montréal directed by Dr. Jean-Pierre Chupin [37]. The competition was open to students and graduates of less than 5 years in the fields of architecture, design, landscape and urban design. In Montreal, the STM (Société de transport de Montréal, the regional transit authority of Montreal) has introduced many improvements to the transit infrastructure and bus stop shelters [38], yet the sites surrounding the shelters have remained largely untouched. Rather than focusing on the (re)design of the bus shelter, this competition aimed to stimulate discussion of the importance of public spaces around transit infrastructure and the role of these spaces in encouraging the use of public transit. Four (4) sites were selected for this competition, each standing for different typologies of bus stop sites in the east of Montreal-varying in context, vegetation cover, proximity to services and housing different models of bus shelters (from the oldest to the newest models in the city). The competition brief presented these sites as those that have the potential to deeply integrate sustainable urban interventions while invigorating the communities in interactive, poetic, critical and meaningful ways. Competitors were encouraged to consider design strategies that integrate technologies, consider renewable energy sources, create playful experiences for users of all ages, and develop climate change awareness, and that can provide innovative adaptations across seasons as well as throughout the day. Competitors were asked to submit two main deliverables: (1) a design that is engaging on a social, environmental, and cultural level, and (2) at least one (or more) written design principles that could be adopted for future implementation for comparable sites around the city [39]. These design requirements are a good representation of blended infrastructure projects identified in the literature.

\section{Received proposals}

The competition received widespread interest with more than two hundred (200) teams registered from thirty (30) countries. Finally, a total of ninety-six (96) projects were submitted by seventy-two (72) teams from more than twenty (20) countries (the full submissions are available on the Canadian Competition Catalogue [40]. The selection of the winning entries was completed by a multidisciplinary jury composed of seven (7) members which included academics in architecture, design and geography, research chairs, practitioners and representatives from collaborating organizations. The judgment criteria focused on clarity and appropriateness, coherence and strength, quality, ability to design around the proposed written principle(s), viability across the four (4) seasons, the needs of the community, environmental design imperatives, and universal access. The submissions varied significantly in their design focus and explored environmental, cultural, social, urban and architectural questions through various modes including placemaking, information transfer, conservation of nature, water management, sensory experiences, 
flexibility and many others. The submissions exhibited the four (4) key polarities described in Figure 4.
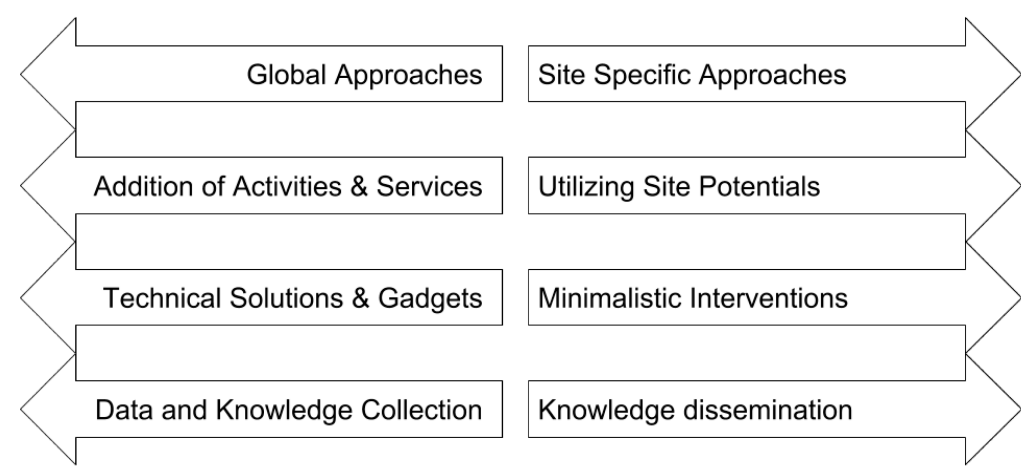

Figure 4. The four (4) polarities exhibited in the competition submissions.

From the ninety-six (96) projects received, the research team was able to extract over two hundred and fifty-three (253) design principles. Like the designs, the principles presented a variety of ideas and concepts. Five (5) main categories of principles were identified (see Figure 5). The most common of which were community development, interactivity, adaptation to climate and urban context, and environmental sustainability. These categories suggest that the designers sought to incorporate in their projects the multi-layered and complex social, cultural environmental, and technological dimensions. They corresponded to design characteristics such as comfort, social interaction, playfulness, and safety. When the principles are compared to the six logics of sustainable architecture as proposed by Guy \& Farmer [35], the most recurring logics are eco-technic, eco-social, eco-centric and eco-cultural (by decreasing order of occurrence). In a previous publication, the principles have also been analyzed based on their distribution between the sites and in relation to the teams' design experience and country of origin [39].

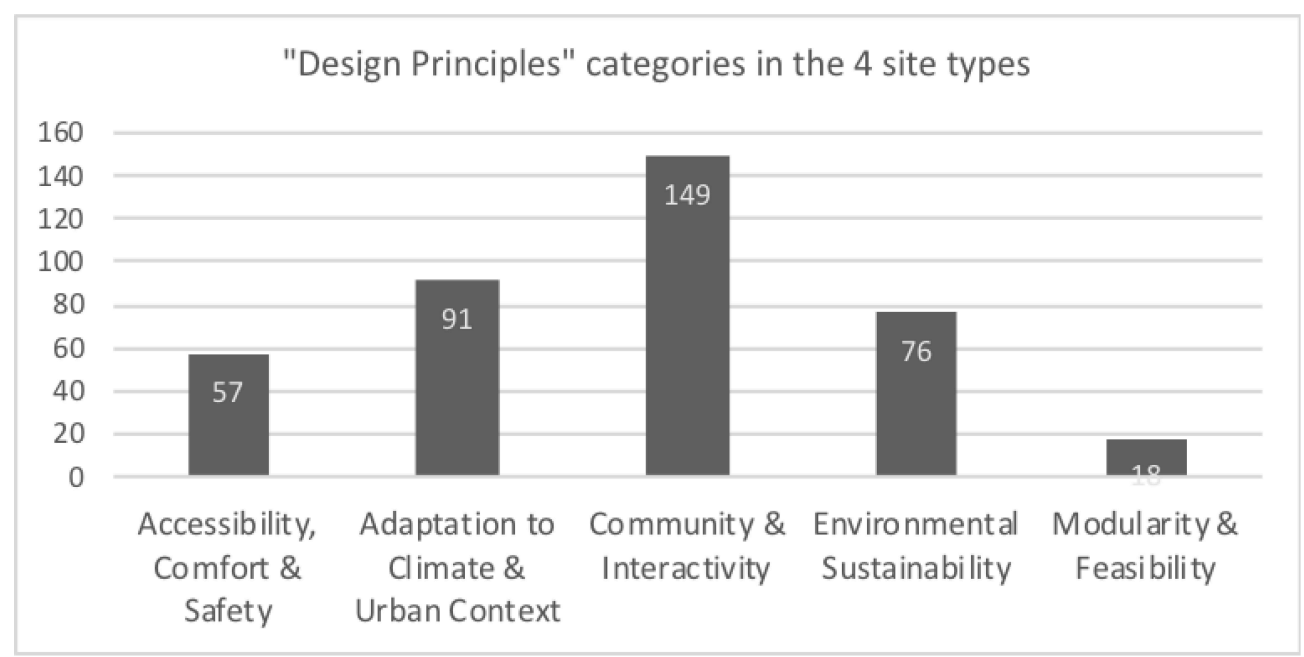

Figure 5. Design principles categorization and occurrence [39]. 


\section{A cartography of the winning and mentioned design proposals}

As indicated in the competition brief, one project was selected as the winner for each of the four (4) sites. Additionally, several honorary mentions were selected by the jury as seen fit. A total of fourteen (14) projects received awards and mentions. Figure 6 presents the mapping of the winning and mentioned projects using the analysis and mapping grid proposed. The mapping was completed based on an in-depth analysis of the formal qualities, the project elements, design principles as well as the jury comments for each of the fourteen (14) projects. Table 1 presents the titles of the analyzed projects, the project's main illustration as well as a sampling of the jury comments.

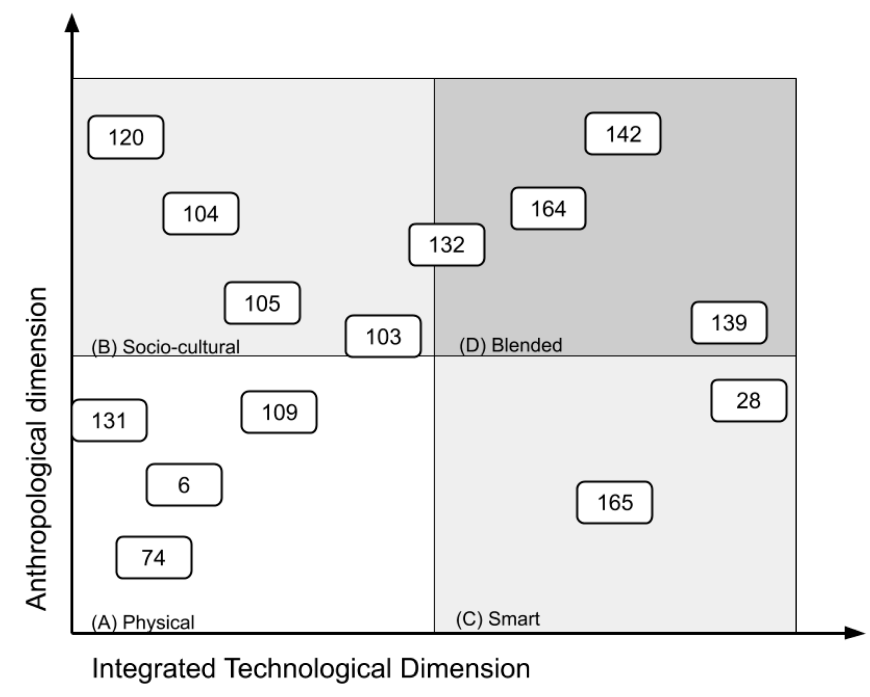

Figure 6. Cartography of the design approaches for the winning and mentioned projects.

Table 1. Winning and mentioned projects and the jury comments.

\begin{tabular}{|l|l|l|l|}
\hline $\begin{array}{l}\text { Project } \\
\text { name }\end{array}$ & $\begin{array}{l}\text { Team members } \\
\text { and number }\end{array}$ & Illustration & Jury comments \\
\hline Tourni & $\begin{array}{l}\text { Merino + Carlos } \\
\text { bruz-Merino } \\
\text { (Canada) }\end{array}$ & $\begin{array}{l}\text { "The jury appreciated the highly social and } \\
\text { cultural dimension of the proposal. The } \\
\text { incentive to read, moreover, to individual } \\
\text { reading in a public place remains a simple and } \\
\text { strong image. The proposed system is as } \\
\text { elegant and flexible since it can be deployed } \\
\text { and moved according to seasons and needs, } \\
\text { both in summer and winter. The design makes } \\
\text { it possible to imagine various ways to animate } \\
\text { the site and takes into account the fact that } \\
\text { this district welcomes many families. Some } \\
\text { members of the jury also saw a reference to } \\
\text { the fishing booths used on frozen lakes. The } \\
\text { balance between security and openness is } \\
\text { what has allowed this project to prevail.” }\end{array}$ \\
\hline
\end{tabular}


Table 1. Cont.

\begin{tabular}{|c|c|c|c|}
\hline $\begin{array}{l}\text { Box of } \\
\text { Change }\end{array}$ & $\begin{array}{l}\text { (132) Adrianna } \\
\text { Karnaszewska + } \\
\text { Sara Niepieklo + } \\
\text { Sylwia } \\
\text { Pedziejewska + } \\
\text { Aleksandra } \\
\text { Przywozka } \\
\text { (Poland) }\end{array}$ & 10 & $\begin{array}{l}\text { "This project proposes to constitute a } \\
\text { luminous forest. Starting from a principle of } \\
\text { modularity, which several competitors have } \\
\text { chosen to adopt, given the repetitive nature of } \\
\text { the bus stop in the city, the project adds a } \\
\text { playful and interactive dimension. The } \\
\text { concept--highly cultural-is intended to be } \\
\text { both educational and informative. It is of a } \\
\text { scale that is as adaptable as it is reproducible } \\
\text { and in so doing it responds to the possibility of } \\
\text { its generalization. The jury considered that } \\
\text { this proposal was an excellent complement to } \\
\text { the generic bus shelter.” }\end{array}$ \\
\hline Funstation & $\begin{array}{l}\text { (104) Rikke } \\
\text { Sandbugt + } \\
\text { Anyana } \\
\text { Zimmermann, } \\
\text { (Denmark \& } \\
\text { Germany) }\end{array}$ & & $\begin{array}{l}\text { "Project resolutely playful. One of the few } \\
\text { proposals adaptable to all season. The focus } \\
\text { given to children characterizes its underlying } \\
\text { didactic canvas." }\end{array}$ \\
\hline Sun Sprout & $\begin{array}{l}\text { (6) Kloe Gagnon } \\
\text { + Adélie Gélinas- } \\
\text { Leguerrier + } \\
\text { Nicole } \\
\text { Kamenovic } \\
\text { (Canada) }\end{array}$ & , & $\begin{array}{l}\text { "This proposal received a mention because of } \\
\text { its claim for a principle of conservation, which } \\
\text { is as simple as it is strong: to work with the } \\
\text { existing resources and natural entities. The } \\
\text { principle is generalizable and it especially } \\
\text { reminds us that all pre-existing conditions of } \\
\text { any design situation carry a potential of } \\
\text { invention." }\end{array}$ \\
\hline $\begin{array}{l}\text { Waterful } \\
\text { Station }\end{array}$ & $\begin{array}{l}\text { (142) Vid } \\
\text { Bogovic + Vlasta } \\
\text { Damjanovic + } \\
\text { Andraz } \\
\text { Hudoklin + Lara } \\
\text { Gligic + Laura } \\
\text { Klenovsek + Sasa } \\
\text { Kolman } \\
\text { (Slovenia) }\end{array}$ &  & $\begin{array}{l}\text { "For this site that received the most proposals, } \\
\text { the deliberations of the jury were more } \\
\text { difficult. This project has emerged as the most } \\
\text { elegant in its design and presentation. } \\
\text { Municipal water management is a real } \\
\text { problem with considerable environmental } \\
\text { implications and it is the only proposal that } \\
\text { has chosen to integrate this issue into the bus } \\
\text { stop. The proposal is very elaborate and } \\
\text { presents itself as a series of systems that } \\
\text { illustrate and implement devices for water } \\
\text { reuse, energy production in a composition } \\
\text { representing the water cycle. The microcosm } \\
\text { of the bus shelter is then transformed into a } \\
\text { true macrocosm. This project is paradoxically } \\
\text { as minimalist as it is didactic." }\end{array}$ \\
\hline
\end{tabular}


Table 1. Cont.

\begin{tabular}{|c|c|c|c|}
\hline $\begin{array}{l}\text { The Green } \\
\text { Light } \\
\text { House }\end{array}$ & $\begin{array}{l}\text { (28) Leila } \\
\text { Hormozi Nejad + } \\
\text { Matthew Coelho } \\
\text { + Gabriel Scott- } \\
\text { Séguin + } \\
\text { Florence } \\
\text { Vanasse } \\
\text { (Canada) }\end{array}$ & 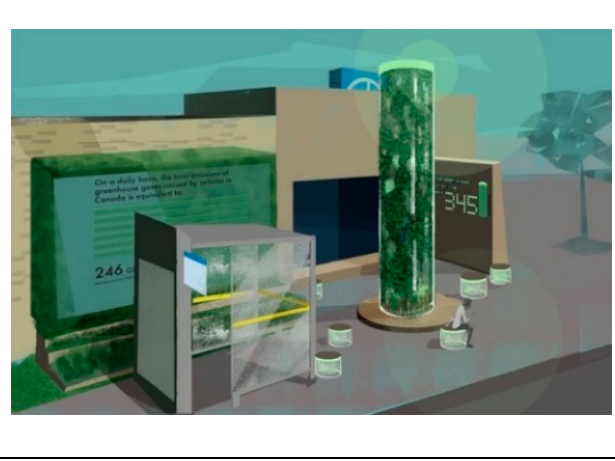 & $\begin{array}{l}\text { "A proposal that is conceivable regardless of } \\
\text { the season. The idea of an urban terrarium, } \\
\text { which can appear as an element of urban } \\
\text { place-marker disconnected from its context, is } \\
\text { nevertheless connected to the metro station in } \\
\text { an astute way. The information exchange } \\
\text { regarding the reduction of GHG's through the } \\
\text { use of the bus is done in a ludic manner and } \\
\text { will therefore appeal to all ages." }\end{array}$ \\
\hline $\begin{array}{l}\text { Hug with } \\
\text { City }\end{array}$ & $\begin{array}{l}\text { (74) Zhu Jinyun } \\
\text { + Qin Jin (China) }\end{array}$ & $E$ & $\begin{array}{l}\text { "The jury wished to mention this proposal, } \\
\text { based on the excesses of public art which } \\
\text { would be put here at the service of the } \\
\text { modesty of bus stops. The project is audacious } \\
\text { and frank, it is as playful - even ironic - as } \\
\text { intriguing." }\end{array}$ \\
\hline - & $\begin{array}{l}\text { (103) Julien } \\
\text { Guerineau + } \\
\text { Axel Demazieres } \\
\text { (France) }\end{array}$ & $=$ & $\begin{array}{l}\text { "This proposition is rich in references as it } \\
\text { makes good use of the famous territorial grid } \\
\text { imagined by the Italian collective Superstudio } \\
\text { in the } 1970 \text { s. The presentation is very } \\
\text { beautiful. It could be transposed to most sites, } \\
\text { but if the components were indeed } \\
\text { transferable, the designers did not clearly } \\
\text { formulate what would make it an } \\
\text { environmental commitment." }\end{array}$ \\
\hline Pause & $\begin{array}{l}\text { (105) Paul } \\
\text { Beaucé (Canada) }\end{array}$ & F & $\begin{array}{l}\text { "Despite its great qualities, this project has a } \\
\text { major flaw: it is not universally accessible. The } \\
\text { elevation marking of the site, the overflow of } \\
\text { the bus shelter ladder is in itself a remarkable } \\
\text { concept that would be convincing on the } \\
\text { urban scale. Would it have been possible to } \\
\text { imagine it on one level while maintaining } \\
\text { verticality?" }\end{array}$ \\
\hline $\begin{array}{l}\text { Be the } \\
\text { Event }\end{array}$ & $\begin{array}{l}\text { (165) Amanda } \\
\text { Barbosa da } \\
\text { Silveira + Lucas } \\
\text { Veloso Schwab } \\
\text { Guerra (Brazil) }\end{array}$ & & $\begin{array}{l}\text { "A system that relies as much on technology as } \\
\text { on the game. The jury appreciated how the } \\
\text { proposal takes the whole site by intervening } \\
\text { on the interstices. The explicit and voluntary } \\
\text { consideration of the constraints of universal } \\
\text { access was emphasized as a remarkable } \\
\text { approach." }\end{array}$ \\
\hline
\end{tabular}


Table 1. Cont.

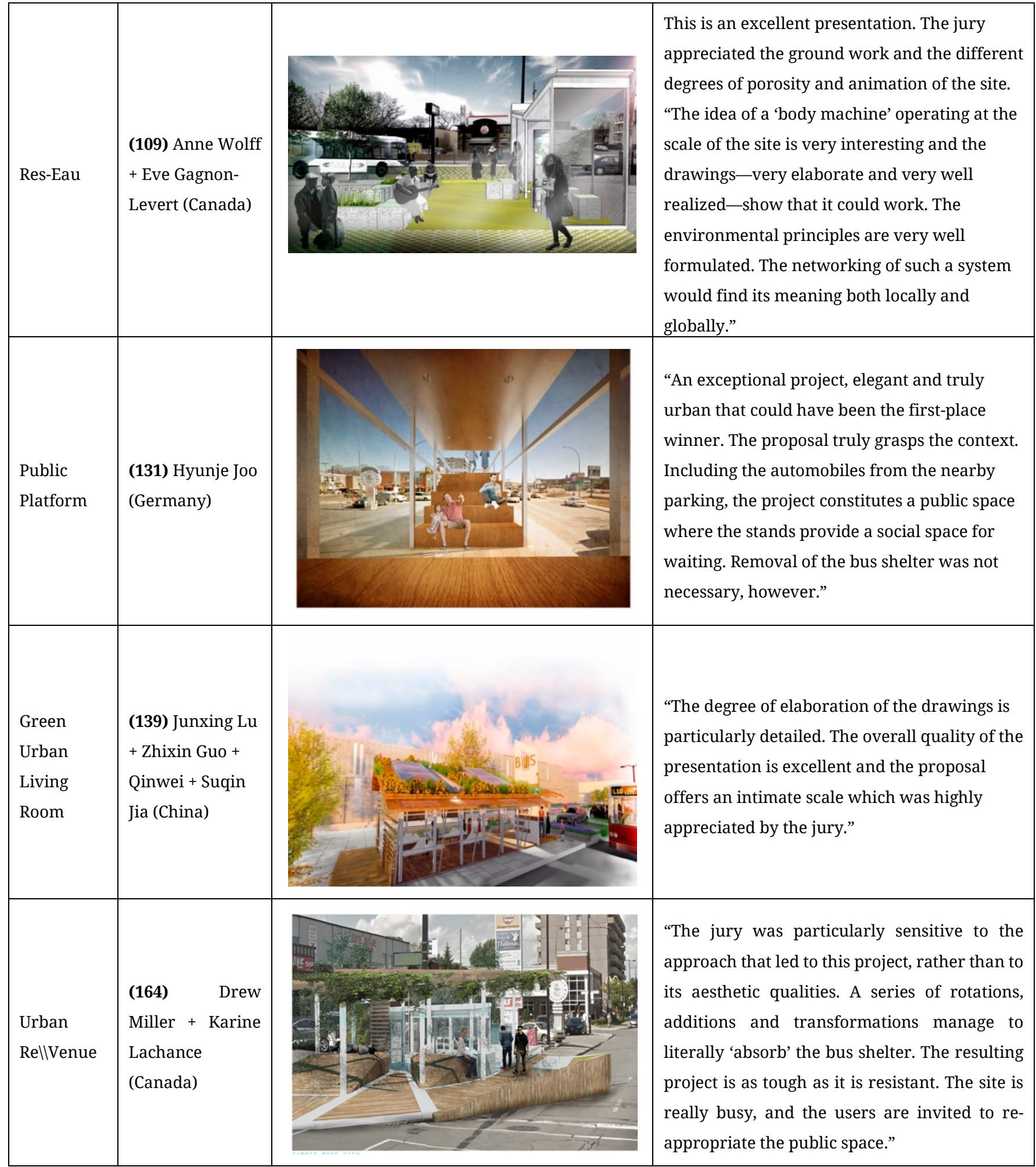

Four (4) projects were identified as using a physical design approach (quadrant A), which aims to improve the spatial quality through physical modifications but do not present any cultural development strategy nor any technological strategies [2]. In a project such as that of team 6 (Kloe Gagnon + Adélie Gélinas-Leguerrier + Nicole Kamenovic, Canada) a new 
structure is annexed to the bus shelter which extends the seating area while protecting and surrounding an existing tree on the site. Although the conservational approach is poetic, it does not directly relate to the social or cultural realities of the site nor does it introduce integrated technological solutions. Two (2) projects were considered to fall into quadrant $\mathrm{C}$, smart approach which prioritizes the use of information technologies to provide improvements to the site. In a project such as that of team 165 (Amanda Barbosa da Silveira + Lucas Veloso Schwab Guerra, Brazil), technological installations are used to augment the effect of the users' movement on the site through light projected on a fully automated green wall installation. The design even proposes the use of automated irrigation and controls for the green wall. Although the approach is interactive and playful, it does not present opportunities for social or cultural development on the site and lacks spaces for self-expression or community appropriation. Four (4) projects were considered to adopt a socio-cultural approach, which focuses on providing opportunities on the site for social interactions, expression of the culture of the location, and possibilities for collective experiences or community appropriations (quadrant B). In a project such as that of team 120 (César Cruz-Merino + Carlos Cruz-Merino, Canada), a series of wood cabins, which can rotate and move, are added to the site to provide for collective spaces for reading or social interactions during both the summer and winter seasons. The cabins are designed with reference to fishing booths, which are culturally relevant in the northern regions of Canada and Quebec. The proposal does not include any technological or information-based additions to the design and is thus placed on the low end of the technological axis. From the fourteen (14) winning and mentioned projects, only three (3) projects directly fall into quadrant $\mathrm{D}$ (i.e., the blended approach) and one (1) project was placed at the border between the blended and socio-cultural approaches. Our sampling hypothesis was therefore confirmed since we found occurrences of blended infrastructure in this set of "light and imagined" projects. These projects aimed at fusing technological and sociocultural elements in the bus shelter sites, resulting in deeply integrated sustainable urban interventions. The specific characteristics of these projects are presented in the discussion section.

\section{DISCUSSION}

\section{Understanding Blended Infrastructure Projects}

The mapping of the winning and mentioned projects of the "More than Waiting for the Bus" competition, shows only four (4) out of the fourteen (14) projects as falling within the quadrant of integrated anthropological and technological approaches-which we consider to be exemplary for blended infrastructure projects. The integration of the project called Waterful Station by team 142 (Vid Bogovic + Vlasta Damjanovic + Andraz Hudoklin + Lara Gligic + Laura Klenovsek + Sasa Kolman) was achieved by 
combining ludic water powered installations which raise awareness about water management issues while generating energy. This design combines playful and social interaction elements, all important characteristics highlighted in the cultural development literature [4] while integrating low energy solutions proposed in the literature relating to smart energy cities [3]. In Urban RellVenue by team 164 (Drew Miller + Karine Lachance), the integration was achieved by creating a connected digital light signalling system that notifies users on the bus arrival time in an augmented social and vegetated shelter, which also helps raise awareness within the community about native species of plants. This project integrates social development strategies such as those proposed by Hakim and Roshanali [7] while proposing information and communication technologies to disseminate information regarding the bus arrival [6]. In Green Urban Living Room by team 139 (Junxing Lu + Zhixin Guo + Qinwei + Suqin Jia), the integration was achieved by combining vegetation and solar panels in an augmented shelter, all described as an urban living room. This presents a cultural regeneration approach [1] to create a sense of communal space around the bus shelter which is supported by solar panels as a mean for clean energy generation [8,9]. Finally, in Box of Change by team 132 (Adrianna Karnaszewska + Sara Niepieklo + Sylwia Pedziejewska + Aleksandra Przywozka), modular reconfigurable units are used to provide lighting, heat and vegetation to the users of the bus. The installation also has modules that provide information and knowledge on climate change and sustainability through interactive screens. The possibility of reconfiguration by the community allows the project to have a cultural development approach-where users are continuously implicated in the production of the space, while also increasing community knowledge, skills and leadership on climate change and sustainability [4,6]. However, the technological integration can be considered more passive, rather than responsive or information driven (which is why its position on the analysis map was at the border between quadrants $C$ and D). These four projects, although different in approach and design content, aim to move the physical improvement of the site to deeply integrate the socio-cultural and technological dimensions to attain a deep sustainable vision. In these imagined and light projects, the integration was achieved through small interventions, which present a clear sense of place that is larger than the sum of their discrete design elements.

To explore the applicability of this mapping methodology to infrastructure projects of different scales, five (5) Montreal projects are selected.

\section{Mapping Major Infrastructure Projects in Montreal}

Since June 2006, Montreal has joined the UNESCO Creative Cities Network by being designated a UNESCO City of Design. This designation is, in fact, an invitation to develop Montreal around creative forces through 
collaboration between citizens, experts, government, and designers. In 2017, the city's 375th anniversary featured many projects and initiatives that use design as their main paradigm — projects which aimed to explore the city's history and to imagine its future as UNESCO City of Design [41]. Additionally, the city and its boroughs have put forward ambitious plans for urban renewal which tackle various major infrastructures including bridges, motorways, and ports. All the selected projects in this analysis are realized projects-located at the opposite side from the case study-on the realization level axis (see Figure 3). These projects vary in their naturefrom lighter to major projects. The details and images of the five infrastructure projects are presented in Table 2. It is important to highlight that the framework proposed does not intend to assess the value of the project-political, economic, social, or environmental. Rather, the assessment is focused on the design approach of the projects. Unlike the projects presented in the case study above, the Montreal projects transcend the underlying future-oriented values embedded in sustainable design projects.

In Illuminating the Jacques-Cartier Bridge project, lighting is used to augment the existing bridge-making it fit within the light infrastructure project definition proposed. In the Bonaventure Legacy-a redesigned entrance to the city, the project consisted mainly of re-designing and renewing the main avenue while also landscaping, vegetating and animating the area with art to create social public spaces. The project for covering the Ville-Marie autoroute was essentially an urban re-stitching project that involved major infrastructure investment for creating a platform on top of a portion of an existing motorway, also creating a new public square (Places des Montrealaises)—the first public square dedicated to women of Montreal and that will be programmed to host a variety of cultural events. The Alexandra Pier project aims to revamp a part of Montreal's port, welcoming tourists arriving from the SaintLawrence river. The project involved creating a new terminal. Finally, the Champlain Bridge is considered one of the largest infrastructure investments in the city and aims to improve the motorway capacity while also presenting a positive image for the city of Montreal. Figure 7 presents the distribution of the projects on the project nature axis.

\section{Project Nature}

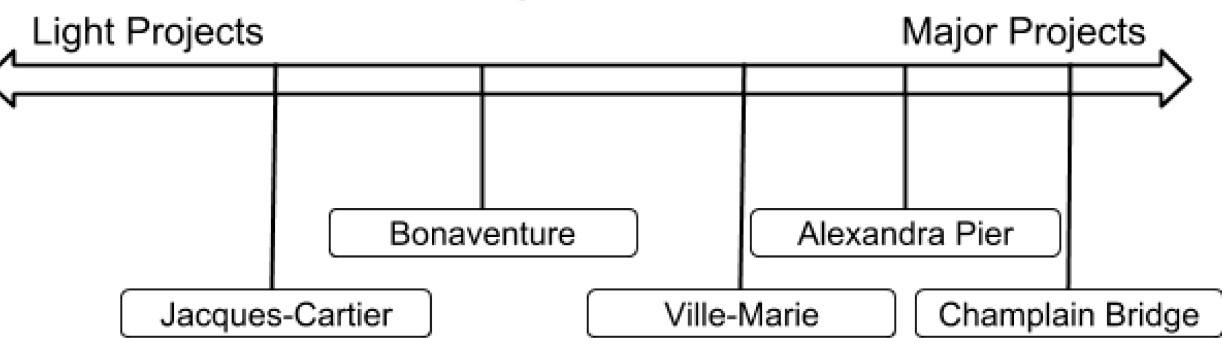

Figure 7. Distribution of selected Montreal projects on the project nature axis. 
Table 2. Selected major infrastructure projects in Montreal.

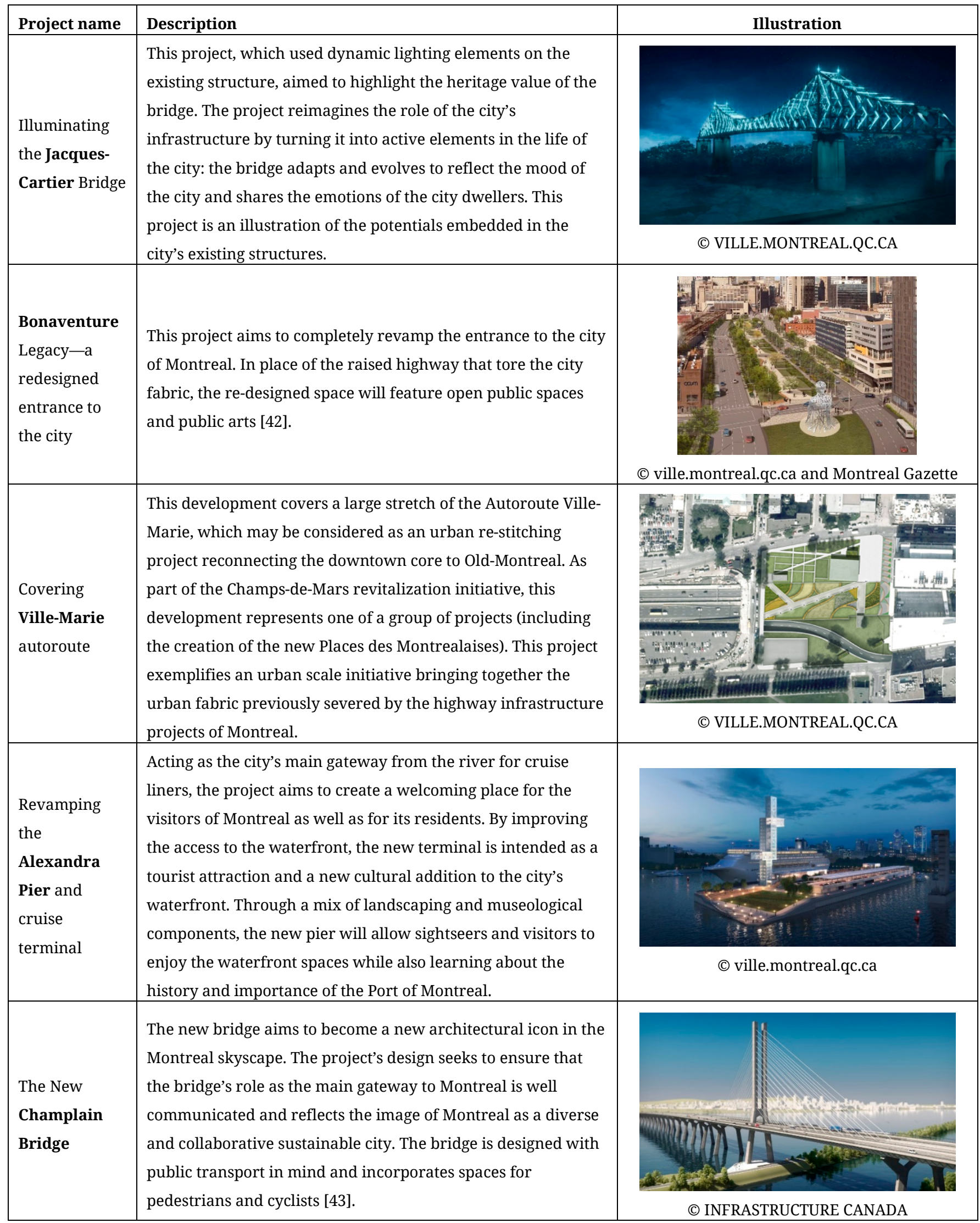


Figure 8 presents the mapping of these five (5) projects on the analysis grid. The results indicate that the realized projects are distributed within the physical and socio-cultural approaches. None of the projects fully achieved the integrated and blended design approach of quadrant D. The results show that, when compared to the light and imagined infrastructure projects of the "More than Waiting for the Bus" competition, these realized infrastructure projects face challenges in achieving the deep integration of technology and socio-cultural dimensions. The Jacques Cartier illumination project is the only project from the sample that moves towards a smart approach by integrating state of the art lighting technologies, which operate in response to the city's mood. However, the projects fall short on the anthropological dimension since they do not present a 'culture and regeneration strategy' [1]. In these projects, rather the cultural integration is only achieved superficially and is focused on projecting a positive image for the city [2]. Of the five selected projects, the illumination project is the "lightest" in nature. On the other hand, the most major project in this sample, the new Champlain bridge, presents a physical design approach lacking cultural development strategies and smart city vision. What is also important to highlight is that the Montreal projects presented exhibit a variety of underlying values-related to economic development, the image of the city, and the improvement of existing infrastructures. These goals are not detached from political or economic imperatives that constitute the complex urban reality of the city. The mapping presented in Figure 8 provides a valid comparison for the projects' design approach but lacks the adequate analysis depth in relation to the value and ethical dimensions. The framework does not consider the connotational meanings that are attached to these projects, nor the controversies or conflicts encountered in their realization. Thus, a more detailed analysis of the context of the project (to understand how the idea came about, who proposed the project, and for what underlying reasons) and mapping of the actor-network (to explore who was affected by the project, who was it intended for, and what compromises had to be made) is required to ground the conclusion of the comparison in the urban reality of Montreal [9-12,22]. However, within the focus on the design approaches of the projects, the findings support the notion that light infrastructure projects do in fact have a large potential to act as deeply integrated sustainable urban interventions in cities. 


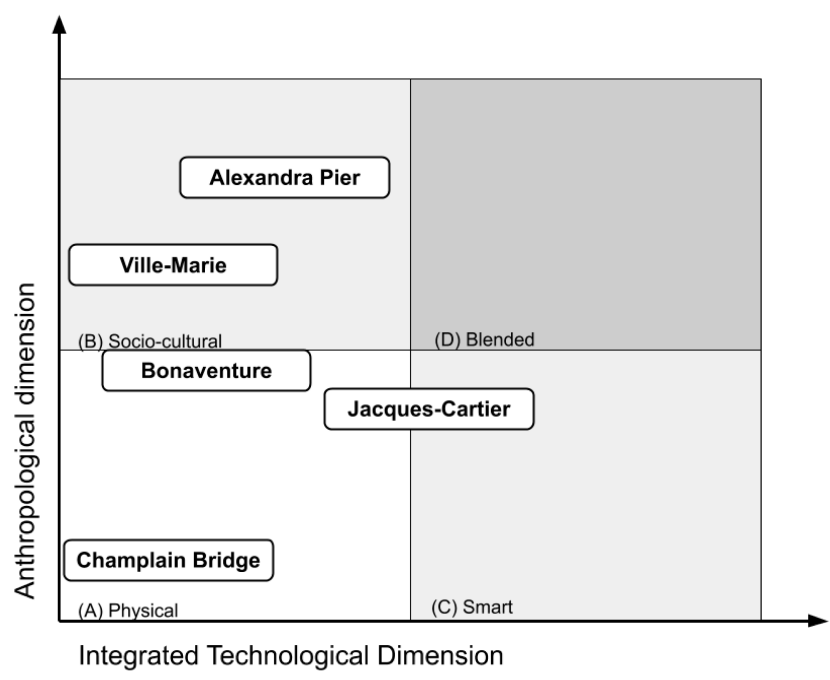

Figure 8. Cartography of the design approaches for the five (5) infrastructure projects in Montreal.

\section{Characteristics and Exemplars for the Four Approaches}

The projects presented in this paper can serve as references to the four (4) approaches proposed in Figure 2. Table 3 summarizes some of the characteristics of each of the approaches and highlights exemplary cases from the examined projects. A physical approach mainly aims to augment the capacity and performance of infrastructure by replacing or adding new elements without the conscious intention of adding ICT or a sociocultural role for the project. This represents a logical approach to urban development which has been argued to be inadequate with the reality of the complex of urban spaces [1,4]. This approach is exemplified in Team 134's Public Platform where the platform serves a functional role and augments the physical capacity of the shelter. It is also seen in the new Champlain bridge, which is designed to have a larger capacity to meet the transit demands of the city. In a socio-cultural approach, the design aims to focus on creating playful experiences, on creating new opportunities at the site, while allowing for users' appropriation and new functions to emerge [1,4]. This is exemplified by Team 104's Funstation where a transit stop is transformed into a playground catered for users of different ages and in the redesign of the Alexandra Pier where museological and reactional activities are added on top of the core transit function. A smart approach is characterized by the integration of information and communication technologies in order to allow for easier access to users and the autonomous efficient management of recourses. This is exemplified in Team 165's Be the Event where the technology is used to collect and present information and to manage the site efficiently. Finally, a blended approach consciously combines aspects of both the sociocultural and smart approaches by using technology and cultural activities. This is exemplified in Team 142's Waterful Station where technology is used to manage water on the site and present information in a playful manner while creating opportunities for engagement. 
Table 3. Selected major infrastructure projects in Montreal.

\begin{tabular}{|c|c|c|c|}
\hline \multirow[t]{2}{*}{ Approach } & \multirow[t]{2}{*}{ Characteristics } & \multicolumn{2}{|c|}{ Exemplar } \\
\hline & & Imagined & Realized \\
\hline (A) Physical & $\begin{array}{l}\text { - } \text { Augmenting the capacity and } \\
\text { performance } \\
\text { - A logical approach to design } \\
\text { - Lacking new cultural functions } \\
\text { - Lacking the integration of ICT or } \\
\text { eco-technologies }\end{array}$ & Team 134-Public Platform & ain Bridge \\
\hline $\begin{array}{l}\text { (B) Socio- } \\
\text { cultural }\end{array}$ & $\begin{array}{l}\text { - A playful approach to design } \\
\text { - Creating lived experiences } \\
\text { - Creating new social and cultural } \\
\text { opportunities at the site } \\
\text { - Allowing for users' and local } \\
\text { appropriations } \\
\text { - Enabling the emergence of new } \\
\text { functions }\end{array}$ & Team 104 & Alexandra Pier \\
\hline (C) Smart & $\begin{array}{l}\text { - A technological approach to } \\
\text { design } \\
\text { - Focusing on the collection } \\
\text { and/or presentation of data and } \\
\text { information } \\
\text { - Enabling users through } \\
\text { communication technologies } \\
\text { - Presenting the site as part of a } \\
\text { larger network of connected } \\
\text { elements in the city }\end{array}$ & Team 165-Be the Event & $\begin{array}{c}\text { (none identified in the } \\
\text { sample) }\end{array}$ \\
\hline (D) Blended & $\begin{array}{l}\text { - A playful approach to design } \\
\text { augmented by technology } \\
\text { - Fusing technology with the } \\
\text { cultural dimension } \\
\text { - Activating the site by creating } \\
\text { new opportunities supported by } \\
\text { technology and innovative } \\
\text { design } \\
\text { - Allowing for the local } \\
\text { appropriations while being } \\
\text { connected to the larger city } \\
\text { elements/resources }\end{array}$ & 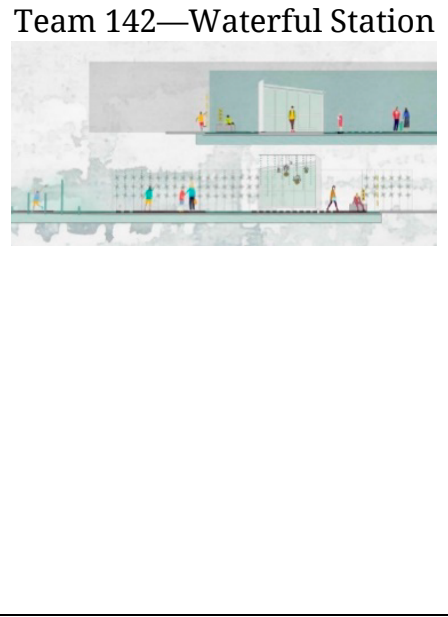 & $\begin{array}{l}\text { (none identified in the } \\
\text { sample) }\end{array}$ \\
\hline
\end{tabular}

\section{CONCLUSIONS}

By investigating the current approaches to urban renewal and development in urban centers, two key approaches were identified: (1) 
socio-cultural integration and (2) technological integration. The literature on the topic highlights the distinction between these two approaches:

- Socio-cultural integration results in cultural development and the experience city vision $[2,4,11]$;

- Technological integration results in a smart or intelligent city vision [3,5,7-9].

The analysis of the literature indicates that both technology and socio-culture are soft infrastructure development domains which can intersect the hard domains of infrastructure (the physical dimension of infrastructure). By overlapping the two future visions of cities (namely the cultural development and smart) with the pillars of sustainability, it appears that they can complement each other to create a combined approach which can lead to a deeply sustainable city vision. The paper names this combined approach to infrastructure, "blended infrastructure projects”. To further understand this new type of infrastructure project, a map composed of two intersecting axes-anthropological and integrated technological dimensions, was proposed as an analysis methodology. A sampling methodology was proposed based on two independent axes: the nature of the project (from light to major infrastructure projects) and the level of realization (from imagined to realized).

This paper focuses on a case study which presents a group of light and imagined infrastructure projects. This case study, which is based on an international competition of design ideas, sought designs to improve the spaces surrounding bus stops: fitting directly within the light and imagined categories selected in the sampling methodology. Fourteen (14) projects that won or received honorary mentions in the competition, were analyzed. The mapping revealed that only four of the projects achieved a deep integration of the anthropological and technological. The four projects presented a unified brand for the destination and presented a sense of place that is unique, tangible and relevant. They offered a conscious and careful integration of elements from the anthropological and technological dimensions that moved beyond cultural development strategies or smart-city approaches for attaining a vision of the sustainable city.

To test the applicability of the mapping approach to different types of infrastructure projects, a smaller sample of realized and more major infrastructure projects was selected. Five realized Montreal infrastructure projects were selected that ranged in their nature (from light to light projects). The analysis of these projects revealed that none of the projects attained the blended approach. The results also indicated that the 'lightest' project, namely the illumination of the Jacques-Cartier bridge, was closest to the 'blended and integrated' approach. These findings suggest that lighter projects have a higher potential for adopting 'blended' approaches, which can constitute deeply integrated sustainable urban interventions. Further research is needed to understand why the major-built projects 
analyzed were not capable of achieving the blended approach. This would necessitate their context (political, economic, social and cultural) to be analyzed in detail in order to understand the connotative meanings inherent in them, the conflicts embedded in their realization, and the power struggles that surrounded their creation.

It is important to highlight in the conclusion that this paper is a primary step in studying this innovative type of infrastructure project-namely blended infrastructure projects. More research is needed to fully investigate this new phenomenon. Three key directions for future studies can be extracted from this examination. (1) To identify pure exemplars for each of the four quadrants proposed in Figure 2. Although the paper uses the examined projects as examples of the different approaches, a more comprehensive study is required to find and document projects that populate each quadrant as well as the possible mutations of the four approaches proposed. (2) To investigate the correlation between the nature of the project (from light to major) and the potential for blended design approaches. This investigation should use a larger sample-which moves beyond Montreal-to specifically investigate and shed light on cases of major projects which exemplify the conscious blending of the socio-cultural and smart approaches. (3) To investigate the movement of projects across the four quadrants in the different realization levels. Such research would aim to track the factors-being political, economic, social or regulatory-that may affect the realization of projects, especially large projects, that exhibit blended approaches. This investigation could potentially focus on specific design competitions and track their progress from the initial submission of ideas to the full realization in the city. This investigation would require using theories from contemporary geography and the social sciences to understand the interactions between the different actors and the projects, as well as the political, economic and ethical underpinnings.

The study provides important insights to researchers and practitioners in the field of urban design, and urban planners when it comes to understanding the dominant urban renewal approaches. It also provides a new method to understand approaches for attaining the sustainable-city vision. The paper also provides a preliminary working definition for blended infrastructure projects as major or light projects where a conscious merging between socio-cultural and technological dimensions is utilized to attain urban transformation, community development, and local economic development, as well efficient resource management [4]. The study also presented an exploration of the imagined and realized manifestation of blended infrastructure projects in the city of Montreal. The investigation revealed that these projects bind the pillars of sustainability, culture and technology. In fact, blended infrastructure projects can be understood as deeply integrated sustainable urban interventions that are relevant to their urban and economic context, appropriate to their users while being environmentally sound. 


\section{AUTHOR CONTRIBUTIONS}

CC and SG designed the study, performed the experiments, made the simulations, analyzed the data and wrote the paper together.

\section{CONFLICTS OF INTEREST}

The authors declare no conflicts of interest.

\section{ACKNOWLEDGMENTS}

Cucuzzella would like to acknowledge the support received through Social Sciences and Humanities Research Council of Canada (SSHRC) and the Concordia University Research Chair program which made this research possible. Goubran would like to acknowledge the support received by SSHRC through the Vanier Canada Graduate Scholarship as well as the support received through Concordia University and the Individualized Program. The authors would also like to thank the Center for Zero Energy Building Studies for their support which helped develop parts of this research. Finally, the authors would also like to acknowledge Stefania Hernandez for her input in the early development phase of the methodology.

\section{REFERENCES}

1. Ferilli G, Sacco PL, Tavano Blessi G, Forbici S. Power to the people: when culture works as a social catalyst in urban regeneration processes (and when it does not). Eur Plan Stud. 2017;25(2):241-58.

2. Grodach C, Loukaitou-Sideris A. Cultural Development Strategies and Urban Revitalization. Int J Cult Policy. 2007;13(4):349-70.

3. Bisello A, D’Alonzo V, Vaccaro R, Hunter GW, Vettorato D, Mosannenzadeh F. Smart energy city development: A story told by urban planners. Cities. 2017;64:54-65.

4. Marling G, Jensen OB, Kiib H. The experience city: Planning of hybrid cultural projects. Eur Plan Stud. 2009;17(6):863-85.

5. Picon A. Smart Cities: A Spatialised Intelligence (Architectural Design Primer). 1st ed. Chichester (UK): Wiley; 2015.

6. Angelidou M. Smart cities: A conjuncture of four forces. Cities. 2015;47: 95-106.

7. Hakim M, Roshanali F. Urban regeneration: An approach to strengthen the social infrastructure of deteriorated areas. J Urban Regen Renew. 2018;11(3):266-77.

8. Yildiz S, Kivrak S, Arslan G. Factors affecting environmental sustainability of urban renewal projects. Civ Eng Environ Syst. 2017;34(3-4):264-77.

9. Bulkeley H, Castán Broto V, Maassen A. Low-carbon Transitions and the Reconfiguration of Urban Infrastructure. Urban Stud. 2014;51(7):1471-86.

10. Junnila S, Heywood C, Luoma-Halkola J, Kuronen M, Majamaa W. Viable Urban Redevelopments-Exchanging Equity for Energy Efficiency. Int J Strateg Prop Manag. 2011;15(3):205-21. 
11. Palermo L. The role of art in urban gentrification and regeneration: aesthetic, social and economic developments. CAPITALE Cult Stud Value Cult Herit. 2014;10:521-45.

12. Dovey K, Ristic M. Mapping urban assemblages: the production of spatial knowledge. J Urban. 2017;10(1):15-28.

13. Simon HA. The Science of the Artificial. Cambridge (US): M.I.T. Press; 1996.

14. Nelson HG, Stolterman E. The Design Way: Intentional Change in an Unpredictable World. 2nd ed. Cambridge (US): The MIT Press; 2012.

15. Boutinet JP. Anthropologie du projet. Paris (France): Presses universitaires de France; 2005.

16. Schön AD. The Reflective Practitioner. New York (US): Basic Books; 1983.

17. Fry T. Design futuring : sustainability, ethics, and new practice. Oxford (UK): Berg Publishers; 2009.

18. Boutinet JP. Psychologie des conduites à projet. Paris (France): Presses universitaires de France; 2014.

19. Cucuzzella C. Is Sustainability Reorienting the Visual Expression of Architecture ? RACAR: Revue d'art canadienne; 2015;40:85-99.

20. Dusch B, Crilly N, Moultrie J. Developing a Framework for Mapping Sustainable Design Activities. In Design Research Society Conference; 2010 Jun 7-9; Montreal, Canada.

21. Lindón A. The lived city: Everyday experiences, urban scenarios, and topological networks. Geogr Helv. 2019;74(1):31-9.

22. Jacobs JM. Urban geographies I: Still thinking cities relationally. Prog Hum Geogr. 2012;36(3):412-22.

23. Lang J. Creating architectural theory: the role of the behavioral sciences in environmental design. New York (US): Van Nostrand Reinhold; 1987.

24. Strong J. Winning by design: architectural competitions. Boston (US): Butterworth-Heinemann; 1996.

25. Chupin JP. Judgement by Design: Towards a Model for Studying and Improving the Competition Process in Architecture and Urban Design. Scand J Manag. 2011;27(1):173-84.

26. Chupin JP, Cucuzzella C, Helal B, editors. Architecture competitions and the production of culture, quality and knowledge: an international inquiry. Montreal (Canada): Potential Architecture Books; 2015.

27. Jonas H. Toward a philosophy of technology. Hastings Cent Rep. 1979;9(1): 34-43.

28. Fletcher KT, Goggin PA. The Dominant Stances on Ecodesign: A Critique. Des Issues. 2001;17(3):15-25.

29. Cucuzzella $\mathrm{C}$. The limits of current evaluation methods in a context of sustainable design: prudence as a new framework. Int J Des Eng. 2009;2(3):243-61.

30. Tukker A, Tischner U. Product-services as a research field: past, present and future. Reflections from a decade of research. J Clean Prod. 2006;14(17): 1552-6.

31. von Schomberg R. The objective of Sustainable Development: are we coming closer? Working paper of the services of the European Commission. 2001. 
Available from SSRN: https://ssrn.com/abstract=2436402 or http://dx.doi.org/10.2139/ssrn.2436402. Accessed 2018 Mar 22.

32. Yudelson J, Meyer U. The world's greenest buildings promise versus performance in sustainable design. London (UK): Routledge; 2013.

33. Garrido P. Business sustainability and collective intelligence. Learn Organ. 2009;16(3):208-22.

34. Mathieu S. Corridart: exposition de la discorde. Archives de Montréal, 2016. Available from: http://archivesdemontreal.com/2016/07/14/corridartexposition-de-la-discorde/. Accessed 2017 May 16.

35. Guy S, Farmer G. Reinterpreting Sustainable Architecture: The Place of Technology. J Archit Educ. 2001;54(3):140-8.

36. Interventions locales en environnement et aménagement urbain. Available from: http://ileau.ca/. Accessed 2017 May 19.

37. Jean-Pierre Chupin. Chaire de recherche sur les concours et les pratiques contemporaines en architecture (Université de Montréal - Architecture). Available from: http://www.crc.umontreal.ca/. Accessed 2017 May 19.

38. Société de transport de Montréal. RAPPORT ANNUEL 2016. Montreal (Canada): Société de transport de Montréal (STM); 2017.

39. Cucuzzella C, Goubran S, Kamel MS. 'More than Waiting for the Bus' Rethinking Sites Surrounding Bus Stops. In: The 1st International Conference on Towards a Better Quality of Life; 2017 Nov 24; Red Sea Region, Egypt. Cairo (Egypt): Housing \& Building National Research Center (HBRC); 2017.

40. Canadian Competitions Catalogue (CCC). Availble from http://www.ccc.umontreal.ca/. Accessed 2019 May 13.

41. Design Montreal. Montréal UNESCO City of Design. Available from: https://designmontreal.com/en/montreal-unesco-city-of-design. Accessed 2018 Mar 22.

42. Riga A. Say goodbye to elevated stretch of Bonaventure Expressway. Montreal Gazette. 2016 Jul 07.

43. Nouveau pont Champlain-Conception architecturale. Infrastructure Canada, 2016. Available from: http://www.infrastructure.gc.ca/nbslnpsl/architecture-fra.html. Accessed 2018 Mar 22.

How to cite this article:

Cucuzzella C, Goubran S. Infrastructure as a Deeply Integrated Sustainable Urban Project. J Sustain Res. 2019;1:e190005. https://doi.org/10.20900/jsr20190005 